Western University Scholarship@Western

Research Program. Impact of the Public Sector on

Research Program. Impact of the Public Sector on

Local Economies Discussion Papers

Local Economies

1975

\title{
Ownership Concentration and Market Power in Urban Land Markets
}

James R. Markusen

David T. Scheffman

Follow this and additional works at: https://ir.lib.uwo.ca/economicsipsle_dp

Part of the Economics Commons

Citation of this paper:

Markusen, James R., David T. Scheffman. "Ownership Concentration and Market Power in Urban Land Markets." Research Program. Impact of the Public Sector on Local Economies Discussion Papers, 003. London, ON: Department of Economics, University of Western Ontario (1975). 


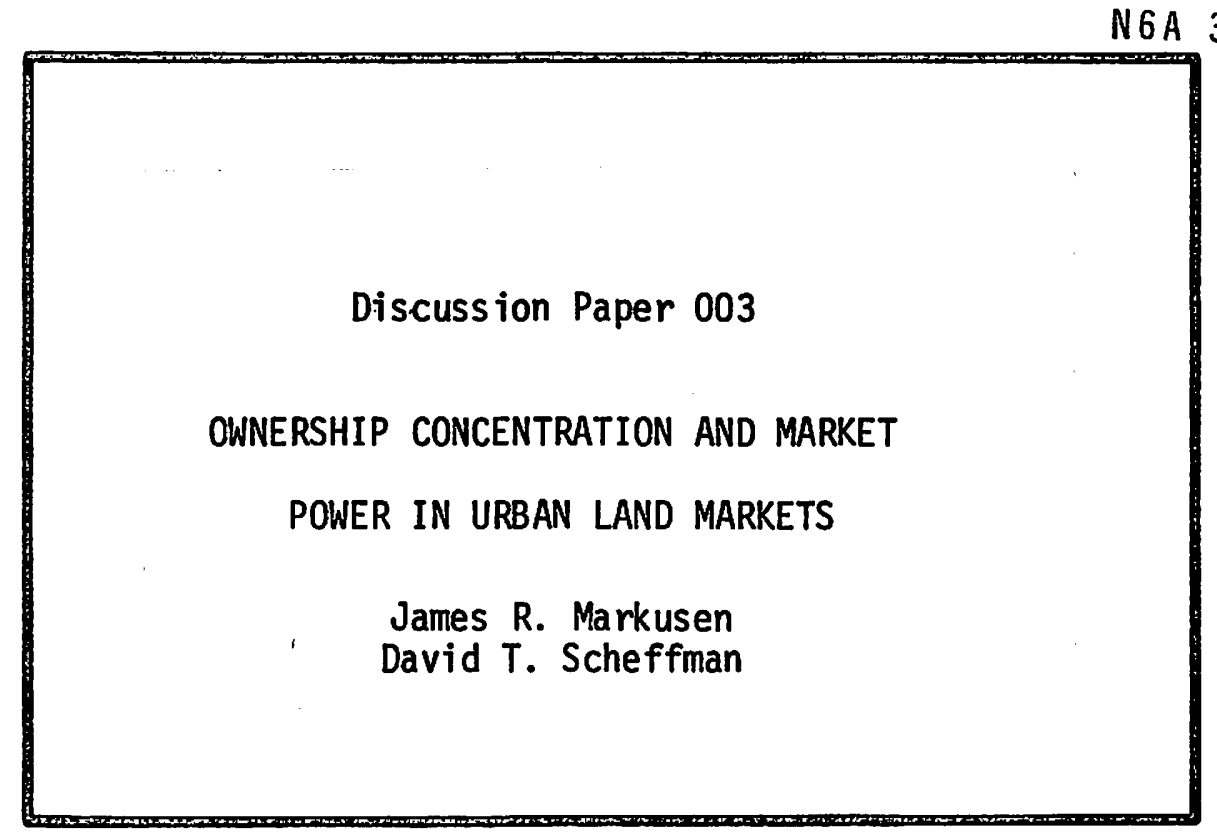

\section{RESEARCH PROGRAM: \\ IMPACT OF THE PUBLIC SECTOR ON LOCAL ECONOMIES}

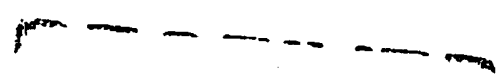

NOV 141975

Department of Economics The University of Western Ontario London Ontario Canada 
Discussion Paper 003

\section{OWNERSHIP CONCENTRATION AND MARKET}

\section{POWER IN URBAN LAND MARKETS}

James R. Markusen

David T. Scheffman

October, 1975 


\title{
OWNERSHIP CONCENTRATION AND MARKET
}

\author{
POWER IN URBAN LAND MARKETS ${ }^{*}, \dagger$
}

\author{
James R. Markusen \\ David T. Scheffman
}

\section{Introduction}

In many North American cities the recent period of inflation has been accompanied by a very rapid increase in land prices, resulting in a signifi-

cant increase in the relative price of housing. ${ }^{1}$ This problem has stimulated considerable public discussion concerning both "who" has been to blame for this problem (developers, "speculators," and government agencies have been the popular targets) and what the possible remedies might be. ${ }^{2}$ In particular, large developers and landowners have been accused of restricting development and raising land prices for their own gain. If the land market is perfectly competitive, then this is not possible, and the perceived problem is purely a distributional, rather than an allocative matter, with the confusion in public discussion arising merely from a misunderstanding of the role of Ricardian rents in competitive markets. For example, the fact that an individual owning a farm near an urban area can sell it at a price in excess of equivalent agricultural land elsewhere does not, of course, imply that the landowner has raised the price above competitive levels. However, in many cases, part of the perceived problem may be allocative if agents in the market for undeveloped land have market power. ${ }^{3}$

This latter allocative issue is one which has received surprisingly little attention in the literature concerned with urban land markets, where competitive conditions are generally assumed to prevail. This is in spite 
of the fact that casual empiricism suggests that concentration in the ownership of undeveloped land may be a fairly common phenomenon. 4 In this paper we develop a theoretical analysis of the effect of concentration of ownership on the allocation of resources in urban land markets, focussing on the relationship between market structure and the spatial distribution of occupancy and land prices in an urban area. We will show that concentrated ownership always confers potential market power on large landowners, and that exercised market power necessarily distorts the spatial distribution of occupancy and land prices. In particular, we show that leapfrog development is one possible result of exercised market power, providing a possible explanation for this common urban phenomenon.

Our analysis will address the following questions: 1) What is a meaningful concept of concentration in the context of 1 and markets? 2) What is the relationship between concentration and the existence of market power? 3) What is the distinction between Ricardian rents and the return to market power in land markets? and 4) What are the allocative effects of exercised market power? Before proceeding with our analysis, we will clarify the issues addressed in these four questions, by discussing them briefly in turn.

The first question arises because the land market requires a definition of concentration which is different from those commonly applied to other industries. The usual problem encountered in defining concentration is that of determining a suitable definition of the industry, i.e., deciding which firms are in the industry. For an urban land market the problem is to determine the appropriate universe of 1 and.

Since concentration in an industry does not necessarily imply the existence of market power unless there are significant barriers to entry, deviations in market structure from perfect competition cannot generally be 
$-i i i-$

inferred simply on the basis of concentration. As we will see, however, in the market for urban land concentration itself is a barrier to entry, and so deviation from competition can be inferred on the basis of concentration. The third question is of particular importance since much of the public discussion of land prices seems to misinterpret Ricardian rents as returns to market power. This confusion could lead to serious errors in the choice of appropriate policies. In our analysis of the fourth question we examine the effect of exercised market power on the structure of land prices and on the geographical configuration of the urban area. 


\section{The Model}

We will use a model of a circular city which is adapted from Solow's version of the standard urban location model. ${ }^{5}$ Since we wish to examine the relationship between concentration, per se, and market power, we will assume that there is an arbitrarily large amount of homogeneous land so that there are no "entry" barriers resulting from limited supplies of specialized land. For simplicity, we will assume the CBD is a circular region of fixed size with radius $R$ and we will ignore the production aspect of the CBD other than to assume a composite consumption good and composite housing good are produced. The consumption good is produced by a perfectly competitive industry at constant costs. The composite housing good, also produced by a perfectly competitive industry, is a flow of housing services consisting of housing and 1 and in fixed proportions, so that the housing composite is measured by lot size. The supply price of a unit of housing services at distance $x$ from the CBD, excluding the cost of land, is $C(x)$, where $C^{\prime}(x) \geqq 0$. Thus $C(x)$ includes the cost of providing and maintaining serviced 1 and and housing at distance $x$ from the CBD, but not the (rental) cost of the raw 1and. With no loss in generality, we assume that land outside the CBD has no economic use other than for housing.

Households thus consume a single composite consumption good and a composite housing good. Each consumer must travel daily to the CBD and incurs an annual transportation cost of $T(x)$ if he lives at distance $x$ from the $\mathrm{CBD}$, with $T^{\prime}(x)>0$. For simplicity we assume that the population of the city consists of $\mathrm{N}$ identical consumers. We can then summarize each consumer by a utility function $U(c, h)$ (where $c$ measures units of the consumption composite and $h$ measures units of the housing composite), and a 
budget constraint $c+r(x) h+T(x)=w$ (where $r(x)$ is the total rent per unit of the housing composite at distance $x$ from the $C B D$, and the price of the consumption composite is set equal to one). Although in this paper we will focus our attention on the rent gradient, assertions about sales prices can easily be made by appropriate capitalization.

Since consumers are identical, in equilibrium all will achieve the same utility level, independent of where they live. Therefore, if we let $V[r(x), w-T(x)]$ denote the indirect utility function of the representative consumer, the equilibrium rent profile, $r(x)$, must satisfy

$$
V[r(x), w-T(x)]=\bar{v}
$$

where $\bar{v}$ is as yet undetermined. From $(1), r=r(x ; \bar{v})$, and it is easily shown that $\partial r / \partial x<0, \partial r / \partial \bar{v}<0$. Notice that $(1)$ is independent of the structure of the land market.

Let $h(r(x ; \bar{v}), w-T(x))=h(r(x ; \bar{v}), x)$ be the demand for housing of a consumer living at distance $x$ from the CBD. Then, by the usual properties of the indirect utility function,

$$
h(r(x ; \bar{v}), x)=-v_{r} / v_{w}
$$

It is easily seen that $d h / d x>0$.

Let there be $n(x) d x$ consumers residing in the circular ring whose inner radius is $R+x$ and whose outer radius is $R+x+d x$. Their total demand for the housing composite in that ring is $h(x) n(x) d x$. Since this composite is measured by lot size, assuming that all land is available for housing, the total potential supply of the composite in this ring is $2 \pi(x+R) d x$. To allow for the possibility that for some market structures land may be held off the market for some rings, let $\theta(x)$ be the proportion of the land in the 
ring actually occupied in equilibrium. Then, in equilibrium we must have $h(x) n(x) d x=2 \pi \theta(x)(x+R) d x$, which we can write $n(x)=2 \pi \theta(x)(x+R) / h(x)$. Let $\bar{x}$ be the solution of the equation

$$
w-T(x)=0
$$

i.e., $\bar{x}$ is the distance from the CBD at which transportation costs exhaust income. Then clearly whatever the market structure, the maximum radius of the city is $\bar{x}+R$. Now we can write the equilibrium condition for space as

$$
N=\int_{0}^{\bar{x}} n(x) d x=2 \pi \int_{0}^{\bar{x}} \frac{\theta(x)(x+R)}{h(x)} d x
$$

This equilibrium condition is also independent of market structure.

\section{Perfect Competition}

For simplicity we assume that all land is owned by absentee landowners. If the equilibrium rent gradient is $r^{*}(x)$, then the rent per unit accruing to owners of 1 and which is at distance $x$ from the CBD is $r^{*}(x)-C(x)$ (for land actually occupied). Assuming that the land market is competitive, and that the only economic use of 7 and is for housing, if $r^{*}(x)-c(x)>0$, then all land in the ring with inner radius $R+x$ and outer radius $R+x+d x$ will be occupied in equilibrium. Thus, the remaining equilibrium condition for a competitive market is

$$
\theta(x)= \begin{cases}1, \text { for } x \leqq x^{c} & \text { where } x^{c} \text { is defined as the } \\ 0, \text { for } x>x^{c} & \text { solution of } r\left(x^{c} ; \bar{v}^{c}\right)=c\left(x^{c}\right)\end{cases}
$$

Then $R+x^{C}$ is the equilibrium radius of the city. 
This equilibrium is depicted in Figure 1 , where $r^{c}(x)$ is the equilibrium rent gradient. Notice that the vertical distance between $r^{c}(x)$ and $C(x)$ at any $x$ is the Ricardian rent earned by owners of 1 and which is at distance $x$ from the CBD.

\section{Monopoly}

For the land market to be a simple monopoly, one landowner must own all the "available" land. One strong but reasonable definition of the "available" land is all land within $\bar{x}$ of the CBD, where $\bar{x}$, as previously defined, is the distance at which transportation costs exhaust income. In this section we assume that one landowner owns all this land. For this market structure the remaining equilibrium conditions is supplied by the assumption of profit maximization. Given the rent gradient, $r(x ; \bar{v})$, the revenue derived from selling $\theta(x)$ of the 1 and in a ring with inner radius $R+x$ and outer radius $R+x+d x$ is $2 \pi \theta(x)(R+x)[r(x ; \bar{v})-C(x)]$. Thus the remaining equilibrium condition becomes

$$
\left\{\theta(x), x^{m}, \bar{v}\right\}^{2 \pi} \int_{0}^{x^{m}} \theta(x)(R+x)[r(x ; \bar{v})-C(x)] d x
$$

subject to $0 \leqq \theta(x) \leqq 1$, and (1) and (4).

We can set up (6) as an optimal control problem in the following way. From (1), $r=r(x ; \bar{v})$ and $d r / d x=T^{\prime} V_{w} / V_{r}$. By (2), we can write this:

$$
d r / d x=-T^{\prime}(x) / h(r(x ; \bar{v}), x)
$$

Now we can write (6) as a control problem with an isoperimetric constraint $((4))$ 
$-5-$

Figure 1

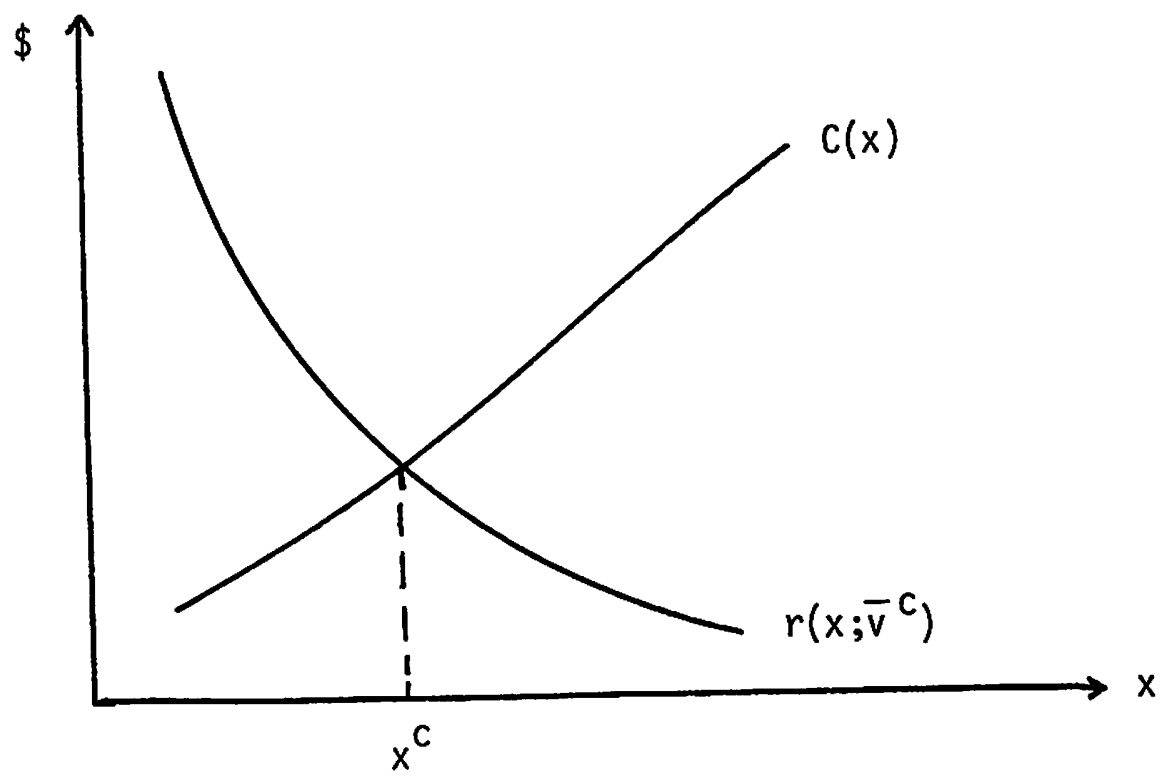




$$
\left\{\theta(x), x^{m}, \bar{v}\right\}^{2 \pi} \int_{0}^{x^{m}} \theta(x)(R+x)[r(x ; \bar{v})-C(x)] d x
$$

subject to $d r / d x=-T^{\prime}(x) / h(r(x ; \bar{v}), x), 0 \leqq \theta(x) \leqq 1$, and

$$
2 \pi \int_{0}^{x^{m}} \frac{\theta(x)(x+R)}{h(r(x ; \bar{v}), x)} d x=N
$$

Identifying $r(x)$ as the state variable and $\theta(x)$ as the control variable, the Hamiltonian for the problem is

$$
\begin{array}{r}
H=2 \pi \theta(x)(x+R)[r(x ; \bar{v})-C(x)+\psi / h(r(x ; \bar{v}), x)] \\
-\lambda\left[T^{\prime}(x) / h(r(x ; \bar{v}), x)\right]
\end{array}
$$

where $\Psi$ is the multiplier for the isoperimetric constraint and $\lambda$ is the usual costate variable.

For our purposes, the only necessary condition for (8) which is of interest is that for each $x, \theta(x)$ is chosen to maximize $H$. Since $H$ is linear in $\theta$, this condition becomes

$$
\theta(x)=\left\{\begin{array}{l}
1, \text { if } 2 \pi(x+R)[r-C+\Psi / h]>0 \\
0, \text { otherwise }
\end{array}\right.
$$

which we can write

$$
\theta(x)=\left\{\begin{array}{l}
1, \text { if }(r(x ; \bar{v})-C(x)) h(r(x ; \bar{v}), x)>-\Psi \\
0 ; \text { otherwise }
\end{array}\right.
$$

Since $\Psi$ can be interpreted as the costate variable for state variable $N$, and $H_{N}=0$, it is easily seen that $\Psi$ is a constant.

of course $(-\Psi)$ can be interpreted as the marginal value of having 
"one" more person living in the city, and $[r(x)-c(x)] h(x)$ is the marginal revenue from selling "one" person land at distance $x$ from the CBD. Thus the interpretation of (11) is clear. However, it is important to notice that unlike the competitive equilibrium it is the marginal cost and marginal benefit per person, not per unit of land which determines the monopoly equilibrium. The reason for this can be illustrated by the following argument. Land sold near the CBD commands a higher rent per unit than land on the outskirts of the city. But the density is also higher near the CBD than further out, so that the unit of land sold near the CBD "uses up" more customers than one unit sold further out. Thus the monopolist must take into account the fact that when he builds an apartment building on an acre of land near the CBD, he reduces demand more than if he sells four quarteracre lots in the suburbs.

We must now determine the sign of $\Psi$. Let $\bar{v}^{m}$ be the utility level achieved in the monopoly equilibrium and let $\bar{v}^{c}$ be the utility level achieved in competitive equilibrium. Of course it must be the case that $\bar{v}^{m} \leq \bar{v}^{c}$. Let $r^{m}(x)=r\left(x ; \bar{v}^{m}\right)$ be the monopoly equilibrium rent gradient and $r^{c}(x)=r\left(x ; \bar{v}^{c}\right)$ be the competitive equilibrium rent gradient. Then, since $\partial r / \partial \bar{v}<0, r^{m}(x) \geqq r^{c}(x)$ for all $x$.

Suppose $\Psi \geqq 0$, and let $\Gamma^{m}=\left\{x \mid\left[r^{m}(x)-C(x)\right] h(x)>-\Psi\right\}$ : Recall that $\left[0, x^{c}\right]=\left\{x \mid r^{c}(x)-c(x) \geqq 0\right\}$. Then, since $r^{m}(x) \geqq r^{c}(x)$, if $\Psi \geqq 0$ we have $\left[0, x^{c}\right] \subset \Gamma$, which means the area occupied in the competitive city is contained in the area occupied in the monopoly city. To prove that this is not possible, let $\gamma(x)=\left[r^{m}(x)-c(x)\right] h(x)$. Then $\gamma^{\prime}(x)=\left[r^{m_{1}}-c^{\prime}\right] h+$ $\left[r^{m}-c\right] h^{\prime}$. If we define $x_{0}$ as the minimum $x$ which solves the equation $r^{m}(x)-c(x)=0$, then since $r^{m_{1}}<0, c^{\prime}>0, h^{\prime}>0$, we have $r^{\prime}(x)<0$ for $x \geqq x_{0}$. Therefore, if $\Psi \geqq 0, r^{m}=[0, \hat{x}]$ where $\hat{x} \geqq x^{c}$. If this is indeed the solution of $(8)$, then $\hat{x}$ is the solution of 
$\max _{\substack{\hat{x}\} \\\{}} 2 \pi \int_{0}^{\hat{x}}(r+x)[r(x ; \bar{v})-c(x)] d x$

subject to:

i) $V(r, x)=\bar{v}$

ii) $2 \pi \int_{0}^{\hat{x}} \frac{x+R}{h} d x=N$

From (12) i) and $i i)$ it is easily seen that $\bar{v}=\bar{v}(\hat{x})$ with $\bar{v}^{\prime}>0$. Therefore we can write (12) as

$$
\max _{\{\hat{x}\}} 2 \pi \int_{0}^{\hat{x}}(R+x)[r(x ; \bar{v}(\hat{x}))-C(x)] d x
$$

for which the first order conditions are

$$
(R+\hat{x})[r(\hat{x} ; v(\hat{x}))-C(x)]+\int_{0}^{\hat{x}}(R+x) \partial r / \partial \bar{v} d \bar{v} / d \hat{x} d x=0
$$

Since $\partial r / \partial \bar{v}<0, d \bar{v} / d \hat{x}>0$, the second term in (14) is negative for any $\hat{x}$, and since $\left[r\left(x^{c}, \bar{v}\left(x^{c}\right)\right)-c\left(x^{c}\right)\right]=\left[r^{c}\left(x^{c}\right)-c\left(x^{c}\right)\right]=0$, the first term in (14) is negative for all $\hat{x}>x^{c}$. Therefore the solution of (14) is such that $\hat{x}<x_{c}$, and so we have finally proved that it cannot be the case that $\Psi \geqq 0$. A monopoly equilibrium of the form required in (12) is compared with the competitive equilibrium in Figure 2. Since $\hat{x}<x^{c}$ and $d \bar{v} / d \hat{x}<0$, $\bar{v}^{m}<\bar{v}^{c}$. But then it must be the case that $r^{m}(x)>r^{c}(x)$ for all $x$, since $d r / d \bar{v}<0$.

Now, using the fact that $\Psi<0$, we can examine the equilibrium structure of the monopoly city by analyzing (11). The first obvious property 
Figure 2

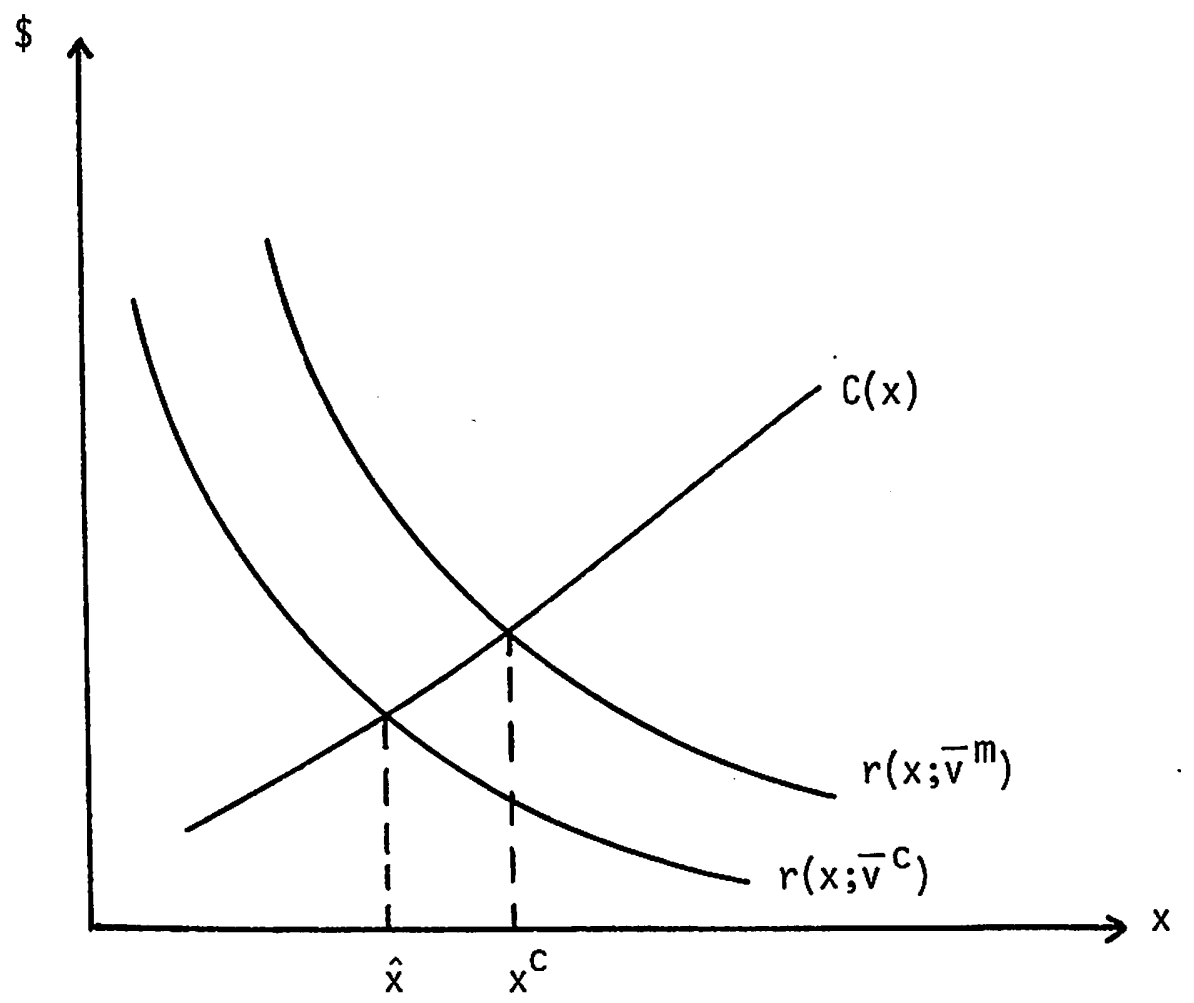


of the structure is that since $\theta(x)$ never takes on a value strictly between zero and one, if the monopolist withholds land in any small ring, he withholds all land in that ring. Let us now consider $\Gamma^{m}=\{x \mid \gamma(x)>-\Psi\}$; for some $\psi<0$. Clearly, $r^{m} \subset\left\{x \mid r^{m}(x)-c(x)>0\right\}$; As shown earlier, $\gamma^{\prime}(x)=$ $\left[r^{m_{1}}-C^{\prime}\right] h+\left[r^{m}-c\right] h^{\prime}$, and since $r^{m_{1}}<0, C^{\prime}>0, h^{\prime}>0$, then $\gamma^{\prime}$ is of indeterminate sign for $x$ such that $r^{m}(x)-c(x)>0$. But this means that $\Gamma^{m}$ may not be of the simple form $\left[0, x^{m}\right]$, but instead, there may be rings of unoccupied land strictly within the outer boundaries of occupancy. Using the popular terminology, we will term this situation "leapfrog" development, which is a phenomenon which seems fairly common in North American urban areas. As we have seen, this cannot occur if the land market is competitive. The reason this may occur is that withholding an "acre" of land inside the city raises the rent gradient more than the amount it is raised by withholding an acre at the edge of the city. This differential may be high enough to overcome the difference in the rent foregone on the more valuable land inside of the city.

In Figure $3,(11)$ is used to depict a monopoly equilibrium where leapfrog development takes place. The equilibrium occupied areas are $\left[0, x_{1}\right],\left[x_{2}, x^{m}\right]$. To understand why leapfrogging may occur, let us examine $\gamma(x)$ in more detail. Clearly a necessary condition for leapfrogging to occur is that $\gamma^{\prime}(x)>0$ for some $x$. Differentiating $\gamma$ we have

$$
\gamma^{\prime}(x)=\left[r^{m_{1}}(x)-c^{\prime}(x)\right] h(x)+\left[r^{m}(x)-c(x)\right]\left[(\partial h / \partial r) r^{m_{1}}(x)-T^{\prime} \partial h / \partial w\right]
$$

Since $r^{m_{1}}(x)=-T^{\prime} / h$,

$$
(\partial h / \partial r) d r / d x-T^{\prime} \partial h / \partial w=r^{m_{1}}(x)[\partial h / \partial r+h \partial h / \partial w]
$$

If we let $H(r, \bar{v})$ be the Hicks-compensated demand for housing, by (1), 
Figure 3

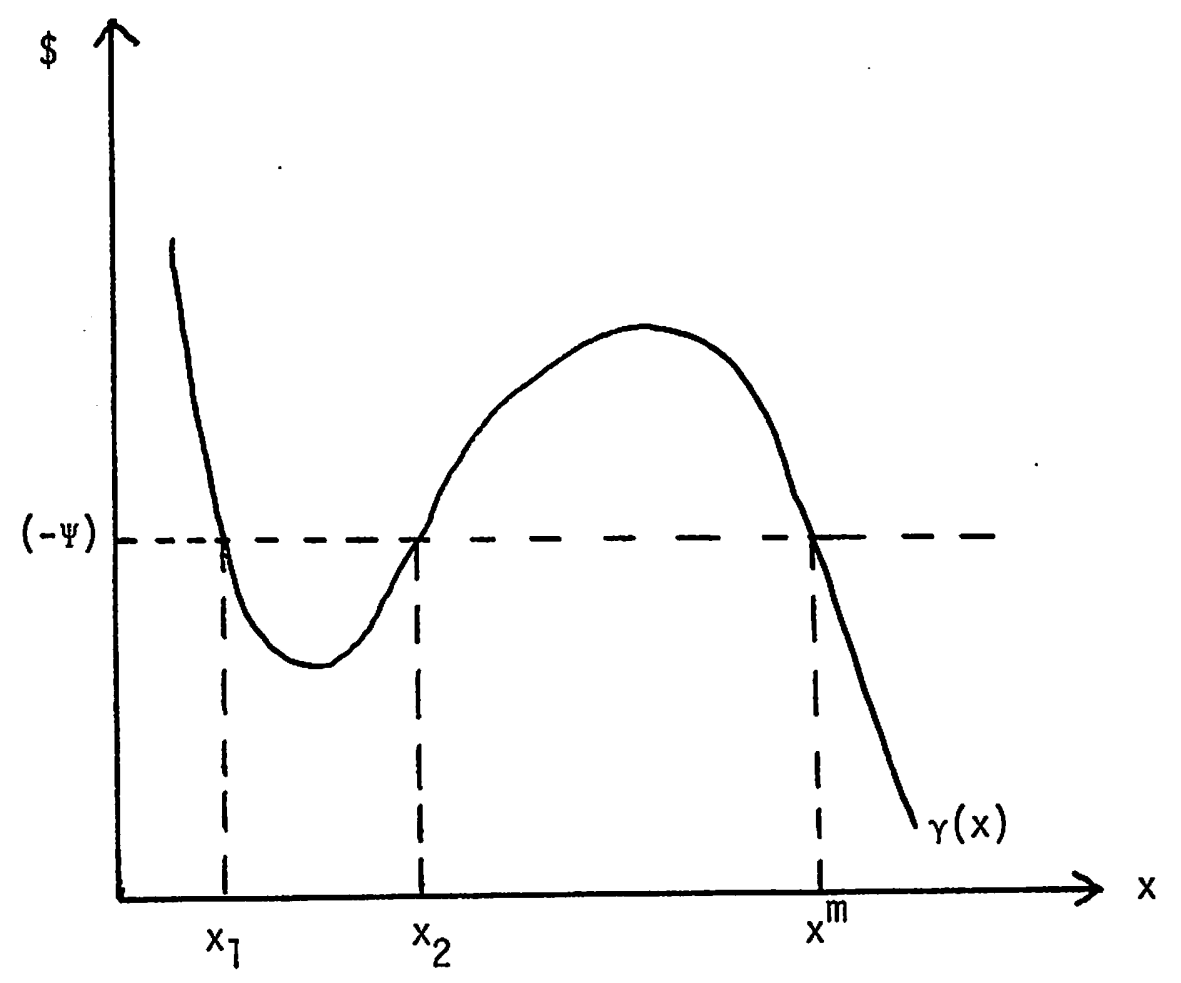


$h\left(r^{m}(x), w-T(x)\right)=H\left(r^{m}(x), \bar{v}^{m}\right)$. Furthermore, by the slutzky equation $2 h / \partial r+h \partial h / \partial w=H_{r}<0$. Therefore, using (18), we can write (17)

$$
r^{\prime}(x)=r^{m_{1}}\left[H+\left(r^{m}-C\right) H_{r}\right]-C^{\prime} H .
$$

Simplifying further, we have

$$
\gamma^{\prime}(x)=r^{m_{1}} H[1+(1-C / r) \varepsilon]-C^{\prime} H
$$

where $\varepsilon$ is the price elasticity of demand of $H(r)$. Since $r^{m_{1}}<0, \varepsilon<0$, we see from (19) that $\gamma^{\prime}$ can only be positive in an elastic region of $H(r)$. Thus a sufficient condition for leapfrogging not to occur is that $H(r)$ be inelastic (for all relevant $r$ ). The intuitive explanation of this condition lies in the fact that the more inelastic is $H(r)$, the greater the relative difference between rents in the interior and the edge of the city. Thus the inelasticity of $H(r)$ makes the cost of foregone rent in the interior too large to make the benefit of withholding interior land profitable.

In Figure 2, we can compare the competitive rent gradient $r^{C}(x)$ and the monopoly rent gradient $r^{m}(x)$. Al though this diagram was drawn on the assumption that leapfrogging does not occur, it is of course true that $r^{m}(x)>r^{c}(x)$ at each $x$, independent of whether leapfrogging occurs or not. In the diagram the distinction between Ricardian rent and monopoly rent can be clearly seen, since $r^{c}(x)-c(x)$ is the Ricardian rent and $r^{m}(x)-r^{c}(x)$ is the monopoly rent derived on land at distance $x$ from the CBD.

\section{4. "Concentrated" Ownership}

of course except for a few historical exceptions, urban land markets are not characterized by monopoly land ownership. Thus where concentration has been a matter of public concern, it has usually been in urban areas in 
which it is thought that a "few" large landowners own a "significant" proportion of the developable land. When accused of artificially raising land prices large landowners have often responded by arguing that there is a considerable amount of topographically similar land in the area which they don't own, and so they are forced to "compete" just like any small landowner. We might paraphrase this argument by saying that although there may be significant concentration, because of large potential supplies there are no significant barriers to entry, at least in the market for topographically similar land.

The crucial flaw in this sort of argument is that land has two important attributes: topography and distance from employment centres. In a particular urban area there may be an effectively unlimited supply of 1 and of similar topography, but there is necessarily a restricted supply of such land within any fixed commuting time to the $C B D$, which results in there being a natural entry barrier. Thus if one landowner owns all 1 and within distance $\bar{x}$ of $C B D$, there is an effective absolute entry barrier. If a small group of landowners own a significant proportion of this land, there is a natural entry barrier which limits the potential competing supply. Concentration measures therefore should use as a basis the totality of developable land within some appropriately chosen range of commuting times to employment centres. Although this basis will be considerably smaller than the totality of topographically similar land, we would expect that urban areas in which a small group of landowners own virtually all the land within an arbitrary range of commuting times are untypical.

To analyze the typical case, for simplicity let us consider a model where there is one large landowner and all land he does not own is held in small parcels. Let $\alpha(x)$ be the proportion of 1 and in the ring with inside 
radius $R+x$ and outside radius $R+x+d x$ which is owned by the large landowner. We will assume that $0 \leq \alpha(x)<1$ for all $x$, so that there is competitively held land which is a perfect substitute for the 1 arge 1 andowner's land at any distance $x$. If $x^{*}$ is the greatest distance at which 1 and is actually occupied in equilibrium, since the equilibrium rent gradient is downward sloping, all competitively held land at a distance of $\leqq x^{*}$ will be sold. Therefore the equilibrium configuration of the city is determined as the solution of

$$
\begin{array}{ll}
\max _{\left\{\theta(x), x^{*}, \bar{v}\right\}} 2 \pi \int_{0}^{x^{*}} \theta(x)(R+x)[r(x ; \bar{v})-C(x)] d x \\
\text { subject to: } d r / d x=-T^{\prime}(x) / h(r(x ; \bar{v}), x) \\
2 \pi \int_{0}^{x^{*}} \frac{[1-\alpha(x)+\theta(x)](R+x)}{h(r(x ; \bar{v}), x)} d x=N \\
0 \leqq \theta(x) \leqq \alpha(x)
\end{array}
$$

Forming the Hamiltonian, we have

$$
\begin{aligned}
H=\theta(x) & (R+x)[r(x ; \bar{v})-C(x)+\psi / h(r(x ; \bar{v}), x)] \\
& +\psi(1-\alpha(x))(R+x) / h(r(x ; \bar{v}), x) \\
& -\lambda\left[T^{\prime}(x) / h(r(x ; \bar{v}), x)\right]
\end{aligned}
$$

The first order conditions for the maximization with respect to $\theta$ becomes

$$
\theta(x)=\left\{\begin{array}{l}
\alpha(x), \text { if }\left[r^{*}(x)-C(x)\right] h(x)>-\Psi \\
0, \text { otherwise }
\end{array}\right.
$$


where, as before, it can be shown that $\psi<0$. As with the case of monopoly, we see that if the large landowner sells any of his land in some small ring, he sells it all. Although (23) is completely analogous to (11), the equilibrium configuration of the city depends critically on $\alpha(x)$. Since by assumption $\alpha(x)<1$, it must be the case that $r^{*}\left(x^{*}\right)=C\left(x^{*}\right)$, since land is competitively held at all distances $x$. We will consider four cases.

Case 1: $\alpha(x)>0$ for all $x$ such that $x_{1} \leqq x \leqq \bar{x}, x_{1}<x^{c}$.

In this case the large landowner will necessarily withhold some of his land from the market, and so the equilibrium rent gradient will be raised above $r^{c}(x)$. The reason for this is that if he does not withhold any 1 and, (23) will be violated for $x$ near $x^{*}$ since in equilibrium $r^{*}\left(x^{*}\right)=c\left(x^{*}\right)$. Therefore in this case leapfrog development will necessarily occur because by withholding some of his land the large landowner leaves unoccupied areas strictly within the boundaries of equilibrium occupancy. In particular, since $r^{*}\left(x^{*}\right)=C\left(x^{*}\right)$ he will withhold all his land "near" $x^{*}$. This is because the "marginal cost" of selling to one more consumer $(-\Psi)$, is always positive, but the marginal benefit of selling to a consumer near $x^{*}, \gamma\left(x^{*}\right)$, is zero. This result shows that even though land which is perfectly substitutable for the large landowner's land is competitively held, he still has market power, and by exercising it causes resources to be misallocated. Notice that the exercised market power of the large landowner raises rents on all occupied 1 and, so that even competitively held land earns monopoly rents.

Let $\Gamma^{c}=\left\{x \mid\left[r^{c}(x)-C(x)\right] h(x)>-\psi\right\}, \Gamma^{*}=\left\{x \mid\left[r^{*}(x)-C(x)\right] h(x)>-\psi\right\}$ and let $A=\{x \mid \alpha(x)>0\}$. 
Case 2: $A \subset \Gamma^{*}$.

If $A \subset \Gamma^{*}$ then the 1 arge 1 andowner will sell all his land, so that the equilibrium is identical to the competitive city. Thus, although he has potential market power ( $i . e .$, he could affect the equilibrium rent gradient by withholding land), he does not exercise it. A necessary condition for $A \subset \Gamma^{*}$ is that the large landowner does not own land "near" the boundary of the competitive city, a situation which seems very unlikely on the basis of observations of large developers' holdings. This is a necessary condition because if he does not withhold land, $r^{*}(x)=r^{c}(x)$, and so $r^{*}\left(x^{c}\right)=c\left(x^{c}\right)$, so that (23) would be violated for his land holdings "near" $x^{c}$. This condition is not sufficient however since it could be the case that $\left[r^{*}(x)-C(x)\right] h(x)<-\Psi$ for $x \ll x^{c}$, in which case the large landowner would withhold land, again producing leapfrogging. Notice that $A \subset \Gamma^{C}$ is not a sufficient condition for all land to be sold, since although if he withholds any land, $r^{*}(x)>r^{c}(x)$, it is not necessarily true that $\left(r^{*}-c\right) h>\left(r^{c}-c\right) h$. Therefore if he owns only valuable interior land, it may still be optimal for him to withhold some of his land.

Case 3: $\alpha(x)=0$ for $x \leqq x^{c}$

In this case the large landowner will not be able to sell any land. In a dynamic framework however, if the city grows enough to encompass his holdings in the hinterlands, Case 2 suggests that he will wait until the competitive boundaries are past the inner boundaries of his holdings before marketing any of his land.

We saw in Cases 1 and 2 that if the large landowner exercises his market power, leapfrogging will necessarily result. This result however depended 
on the assumption that $\alpha(x)<1$. If $\alpha(x)=1$ for some $x$ we have the following situation.

Case 4: $\alpha(x)=1$ for $x_{1} \leqq x \leqq \bar{x}, x_{1}<x^{c}$.

In this case the large landowner owns all the land near the boundary of the competitive city. If he does not withhold any land, then $r^{*}(x)=r^{c}(x)$ and so (23) is violated for his holdings near $x^{c}$. Therefore he necessarily withholds land, and $x_{1}<x^{*}<\bar{x}$, so that he owns the occupied areas furthest from the CBD. The condition $r^{*}\left(x^{*}\right)=C\left(x^{*}\right)$ no longer holds, because no one else holds land near the boundary. In this case, as was true for monopoly, leapfrogging may not occur, since (23) may require only that he withhold land between $x^{*}$ and $\bar{x}$.

As we saw in Case 2, although the large landowner always has potential market power (except in the uninteresting Case 3 ), he may not exercise it, so that the existence of a large landowner does not necessarily imply that a misallocation of resources will result. However, from Cases 1 and 4 we can determine sufficient conditions for misallocation to exist. If leapfrogging exists in equilibrium or if the large landowner owns 1 and at the boundary of equilibrium occupancy, then there has been a misallocation of resources.

5. Quasi-Dynamics

We will now interpret our static model and its results in the context of a growing urban area with the usual comparative statics methodology. We will assume that income in terms of the consumption good (w) and "construction" and servicing costs in terms of the consumption good $(c(x))$ 
are constant, but that population increases over time. First we consider the effect of an increase in $N$ on the equilibrium configuration of the competitive city.

From (1)

$$
r=r(x ; \bar{v}), \text { with } \partial r / \partial \bar{v}<0
$$

so that we can write the equilibrium conditions for the competitive city

$$
\begin{aligned}
& \text { i) } \int_{0}^{L} n[r(x ; \bar{v}), x) d x=N \\
& \text { ii) } r(L ; \bar{v})=C(L)
\end{aligned}
$$

Totally differentiating (25), we have

$$
\begin{aligned}
& n[r(L ; v), L)] d L+\left(\int_{0}^{L} n_{r} \partial r / \partial \bar{v} d x\right) d \bar{v}=d N \\
& \left(r_{L}(L ; \bar{v})-C^{\prime}(L)\right) d L+r_{\bar{v}} d \bar{v}=0
\end{aligned}
$$

Solving for $2 L / \partial N$ and $\partial \bar{v} / \partial N$ from (26),

$$
\begin{aligned}
& \text { i) } \frac{\partial L}{\partial N}=\frac{r_{\bar{v}}}{n(L) r_{\bar{v}}-\left(r_{L}(L)-C^{\prime}(L)\right)\left(\int_{0}^{L} n_{r} \partial r / \partial \bar{v} d x\right)} \\
& \text { ii) } \frac{\partial \bar{v}}{\partial N}=\frac{-\left(r_{L}(L)-C^{\prime}(L)\right)}{n(L) r_{\bar{v}}-\left(r_{L}(L)-C^{\prime}(L)\right)\left(\int_{0}^{L} n_{r} \partial r / \partial \bar{v} d x\right)}
\end{aligned}
$$


Since $n(r, x)=1 / h(r, x), \partial n / \partial r=-h_{r} / h^{2}$, which is $>0$, assuming housing is a normal good. ${ }^{6}$ Also, $r_{v}<0$, and $r_{L}(L)=r^{\prime}(L)<0$, so that

$$
\frac{\partial L}{\partial N}>0, \frac{\partial \bar{V}}{\partial N}<0
$$

Therefore,

$$
\frac{\partial r}{\partial N}=\frac{\partial r}{\partial \bar{V}} \frac{\partial \bar{V}}{\partial N}>0
$$

Thus we see that the effect of an increase in $N$ on the equilibrium competitive city is to increase the size of the city, lower all citizens' well-being, increase density at every $x$, and increase the equilibrium rent at every distance $x$. This can easily be seen in Figure $I$, using the fact that $\partial r / \partial N>0$.

Now let us consider the effect of an increase in population on the monopoly city. As with the competitive city, it is clear that when $N$ increases, $\bar{v}^{\mathfrak{m}}$ will fall and so $r^{m}(x)$ will rise at every $x$ : Since the rent gradient shifts up, intuition suggests that the size of the monopoly city will increase, and in particular, previously "leapfrogged" areas will fill in. To analyze this conjecture we must consider (11). Since $(-\Psi)$ is the marginal value of additional population, we would expect that the usual case would be that $\partial(-\psi) / \partial N \leqq 0 .^{7}$ Again, letting $\gamma(x ; \bar{v})=[r(x ; \bar{v})-$ $C(x)] h(r(x ; \bar{v}), x)$,

$$
\frac{\partial \gamma}{\partial \bar{v}}=r_{v}\left[h+(r-c) h_{r}\right]
$$

which we can write

$$
\frac{\partial \gamma}{\partial \bar{v}}=r_{\bar{v}} h[1+(1-C / r) \varepsilon]
$$


where $\varepsilon$ is the price elasticity of demand of $h(r)$. Therefore a sufficient condition for $\partial \gamma / \partial N>0$ is that $h(r)$ is inelastic. Since $\varepsilon<\varepsilon$ if $h$ is a superior good, then if $\varepsilon \geqq-1$, leapfrogging will not occur 8 and the city will grow as $N$ grows. However, if leapfrogging occurs, then $\varepsilon \ll-1$ for some $x$, and so $\varepsilon \ll-1$ for some $x$. In this case, by (31) we may have $\partial \gamma / \partial N<0$ for some $x$, and therefore some previously occupied areas may become vacant as $\mathrm{N}$ grows. By (11), for "sma11" changes in $\mathrm{N}$, these previously occupied areas will have been adjacent to vacant areas, so that if leapfrogging occurred, as $N$ grows the "leapfrogged" areas may increase in size!

The analysis of the growing city with concentrated ownership is identical to that for the monopoly city. However, it is of interest to note that in Case 2 (all land sold by the large landowner), an increase in $\mathrm{N}$ may cause the large landowner to now withhold land, since, although $r$ will rise, $\gamma$ may fall sufficiently so that (23) no longer holds for some of the previously sold land.

\section{Summary and Conclusions}

In this paper we analyzed the allocative effects of concentration of ownership in urban 1 and markets. We showed that the universe of 1 and chosen as the basis of a measure of concentration should be delimited by land within an appropriate range of commuting times to employment centres. The distinction between Ricardian rents and returns to market power was clarified. It was shown that concentrated ownership always confers potential market power on the 1 arge landowners and that sufficient conditions for the existence of a misallocation of resources in the land market were either the existence of leapfrogging, or that a large 
landowner owns 1 and near the outer boundary of the city.

The empirical validity of our results depends of course on their sensitivity to alternate assumptions. Aside from the static nature of the model, the critical assumptions would appear to be that land is homogeneous and consumers are identical. It seems obvious that homogeneous 1 and is only an analytical convenience, and that the actual heterogeneity of 1 and makes the existence of concentration more likely. It is somewhat less obvious, but nonetheless true, that the assumption of identical consumers is also merely for technical purposes.

Casual empiricism suggests that the sufficient conditions for the existence of resource misallocation are commonly found in many North American urban areas. Developers of course generally do hold land near the boundary of the city. Leapfrog development also appears to be a fairly common phenomenon. Of course some leapfrogging is simply the result of topography, and thus has nothing to do with market power. In other cases leapfrogging is apparently the result of zoning. However, it may be wrong to attribute such leapfrogging to zoning, since if ownership is concentrated, zoning may largely reflect developers' preferences.

There remains, of course, the empirical question of whether or not concentration exists. Our analysis has shown that this is a question which ought to be answered. 


\title{
FOOTNOTES
}

\begin{abstract}
* The research contained in this paper was funded by the Ontario Economic Council. The authors gratefully acknowledge this support.
\end{abstract}

tThe authors thank Mark Frankena and Arthur Robson for their very helpful comments.

1For example, in Toronto during the period 1972-1974 the price of residential building lots increased more than $100 \%$, with the average 1ot price exceeding $\$ 25,000$ in early 1974. Several other Canadian cities have had similar experiences.

${ }^{2}$ The government of Ontario singled out "speculative activity" as a prime cause and enacted legislation in April 1974 which was intended to stop "speculation" by taxing the gains to "speculation." The developers blamed the government for the problem, claiming that the complicated process of registering subdivisions and inadequate municipal servicing were restricting the supply of serviced land.

${ }^{3}$ An agent has market power if he can affect the prices at which he trades.

${ }^{4}$ Two recent studies of the Toronto area have suggested that a sma11 number of the large developers own a large percentage of the available 7and. A candidate running for the provincial parliament of Ontario claimed that two developers owned more than $90 \%$ of the available 1and in London, Ontario (a city of approximately 250,000 ). 
"On Equilibrium Models of Urban Location," in Essays in Modern Economics, M. Parkin (ed.), Longmans, 1973.

${ }^{6}$ For the competitive equilibrium to be stable, it must be the case that

$$
\int_{0}^{L} n_{r} \partial r / \partial \bar{v} d x<0 .
$$

If we let $\beta(N)$ be the maximized value of monopoly profits, then clearly $\beta(N) \leqq W N$, suggesting $\partial(-\Psi) / \partial N \leqq 0$ is the likely case, at least for "large" $N$. If $\partial(-\Psi) / \partial N>0$ the monopoly city might shrink with an increase in $\mathrm{N}$.

$$
{ }^{8} \text { See equation (20) and associated discussion. }
$$

